\title{
USE OF DEXMEDETOMIDINE AS ADJUVANT IN OBLIQUE SUBCOSTAL TRANSVERSUS ABDOMINIS PLANE BLOCK
}

\author{
Swati Bisht ${ }^{1}$, Sunitha Kuruvadi Sreeramalu², Gopal Sadanand ${ }^{3}$ \\ ${ }^{1}$ Associate Professor, Department of Anaesthesiology, Vydehi Institute of Medical Sciences \& Research Centre, Bangalore. \\ 2Professor, Department of Anaesthesiology, Vydehi Institute of Medical Sciences \& Research Centre, Bangalore. \\ 3 Professor \& HOD, Department of Anaesthesiology, Vydehi Institute of Medical Sciences \& Research Centre, Bangalore.
}

\section{ABSTRACT}

Effective analgesia is desirable in ambulatory surgeries. Oblique subcostal transversus abdominis plane block is a good option for providing post-operative analgesia. Dexmedetomidine used as an adjuvant with local anaesthetic results in a longer lasting analgesia and reduces the post-operative opiod supplementation. This helps in early ambulation and early discharge of the patient. The objective of this study was to assess the efficacy of adding dexmedetomidine to $0.25 \%$ bupivacaine in bilateral ultrasound guided oblique subcostal transversus abdominis plane block in patients undergoing laparoscopic ovarian cystectomy.

\section{METHOD}

One hundred patients posted for laparoscopic ovarian cystectomy were randomly allocated in two groups of 50 each: group BD received bilateral $20 \mathrm{ml} 0.25 \%$ bupivacaine and $0.5 \mathrm{mcg} / \mathrm{kg}(2 \mathrm{ml})$ of dexmedetomidine; while Group B received $20 \mathrm{ml} 0.25 \%$ bupivacaine and $2 \mathrm{ml}$ normal saline. We assessed pain by VAS every 2 hours for 24 hours, time for first analgesic, i.e. morphine demand and totally used morphine doses for 24 hours. Adverse effects were also noted. It was a double blinded study.

\section{RESULTS}

There is a statistically significant difference in the time for first morphine and pain score for 24 hours between the two methods ( $p$ value $<0.05$ ). The time for the first demand of rescue analgesia i.e. morphine was earlier in group B, 5.91 \pm 1.28 hours as compared to group BD, i.e. $10.18 \pm 2.12$ hours. The total morphine consumption in 24 hours ( $p$ value $<0.05$ ). The average VAS score for the 24 hours was lower in group BD 3.20 \pm 0.579 than in group B, i.e.4.91 \pm 1.63 . $(\mathrm{p}<0.05)$.

\section{CONCLUSIONS}

Ultrasound guided oblique subcostal block using dexmedetomidine with bupivacaine provides longer analgesia with significant morphine sparing effect.

\section{KEYWORDS}

Dexmedetomidine, Bupivacaine, Oblique Subcostal Transversus Abdominis Plane Block.

HOW TO CITE THIS ARTICLE: Bisht S, Sreeramalu SK, Sadanand G. Use of dexmedetomidine as adjuvant in oblique subcostal transversus abdominis plane block. J Evolution Med Dent Sci 2016;5(2):106-108, DOI: 10.14260/jemds/2016/25

\section{INTRODUCTION}

Transversus Abdominis Plane (TAP) block is a regional anaesthetic technique that blocks neural afferents of anterolateral abdominal wall. Rafi. ${ }^{1}$ and McDonnel et al. ${ }^{2}$ were the first to describe this block. Hebbard et al. ${ }^{3}$ described an ultrasound guided approach to the TAP block. Three approaches for the TAP block described are the subcostal, midaxillary and lumbar triangle of Petit. ${ }^{4}$ The oblique subcostal approach was associated with a larger area of spread (T7-L1) whereas it was only T10-L1 with the other two approaches. ${ }^{5}$ Unfortunately, the block duration is limited to the effect of administered local anaesthetic. Dexmedetomidine is a selective alpha 2 adrenergic agonist with analgesic and sedative properties. ${ }^{6}$ Its use with bupivacaine either epidurally or intrathecally is associated with prolongation of local anaesthetic effect.7,8,9,10,11 Laparoscopic ovarian cystectomy is associated with post-operative pain of moderate intensity and in the immediate postoperative period.

Financial or Other, Competing Interest: None.

Submission 31-12-2015, Peer Review 01-01-2016,

Acceptance 04-01-2016, Published 05-01-2016.

Corresponding Author:

Dr. Swati Bisht,

SG 304, Shriram Spandhana Appartments,

Challaghatta,

Bangalore-560037.

E-mail: swati_bisht@hotmail.com

DOI:10.14260/jemds/2016/25
Laparoscopic surgeries are mainly day care surgeries. Good analgesia is an important requirement in day care surgeries. A major component of pain experienced by patient after abdominal surgeries originates from the abdominal wall incision. ${ }^{12}$ Oblique subcostal TAP block with its wider spread provides good post-operative analgesia. There is limited data on the efficacy of dexmedetomidine as adjuvant in TAP block. ${ }^{13}$ in this study we aim to study the efficacy of dexmedetomidine as adjuvant to bupivacaine in TAP block in patients undergoing laparoscopic ovarian cystectomy.

\section{MATERIALS AND METHODS}

After approval from the faculty ethical committee 100 ASA1 and 2 patients posted for laparoscopic ovarian cystectomy were included in this study. Exclusion criteria were patient refusal, history of cardiac or respiratory disease, coagulation disorders, local infection at the site of block, allergy to local anaesthetics, psychological disorders, chronic use of pain medications or adrenoreceptor agonists or antagonists. During the preoperative assessment, patients were familiarized with visual analogue pain scale for pain assessment $0-10$, 0 meaning no pain and 10 meaning worst pain imaginable. The preoperative investigations included $\mathrm{Hb}$, HCT levels, blood sugar levels, serum electrolytes, urea, creatinine, liver function tests, coagulation profile, chest $x$-ray and pulmonary function tests. 
The patients were randomized using a computer generated program and allocated to 2 groups- Group BD and Group B. Group BD received bilateral $20 \mathrm{ml} 0.25 \%$ bupivacaine and $0.5 \mathrm{mcg} / \mathrm{kg}(2 \mathrm{ml})$ of dexmedetomidine; while Group B received $20 \mathrm{ml} 0.25 \%$ bupivacaine and $2 \mathrm{ml}$ normal saline. We assessed pain by VAS every 2 hours for 24 hours, time for first analgesic i.e. morphine demand and totally used morphine doses for 24 hours. Adverse effects were also noted. It was a double blinded study. All patients were pre-medicated with Inj. glycopyrrolate $0.5 \mathrm{mcg} / \mathrm{kg}$ and Inj. midazolam $0.03 \mathrm{mg} / \mathrm{kg}$. Monitoring included NIBP, HR, pulse oximetry and end tidal C02. Induction was with inj. fentanyl $2 \mathrm{mcg} / \mathrm{kg}$, Propofol $1-2 \mathrm{mg} / \mathrm{kg}$ and vecuronium $0.1 \mathrm{mg} / \mathrm{kg}$. Tracheal intubation was done with endotracheal tube no. $7 \mathrm{~mm}$ ID. Maintenance of anaesthesia was with N2O, 02 (FiO2 0.35) and sevoflurane (11.2 MAC).

Ventilatory settings were adjusted to maintain ETCO2 between 35-40 mmHg and Sp02-95-100\%. A PEEP of $5 \mathrm{~cm} \mathrm{H2O}$ was used in all patients. All patients were placed in dorsal lithotomy position. Umbilical incision was made and $\mathrm{CO} 2$ was insufflated through the port. Intra-abdominal pressure was not to exceed $20 \mathrm{~cm} \mathrm{Hg}$. Two secondary ports were placed $5 \mathrm{~cm}$ superior and lateral to the pubic symphysis. The cases were all done by the same surgical team and was completed in 60-75 minutes. Following skin closure, bilateral oblique subcostal transversus abdominis plane injection was performed with linear probe that was placed in the midline of the abdomen $2 \mathrm{~cm}$ below the xiphisternum and moved laterally along the subcostal margin. The rectus abdominis and transversus abdominis muscles were identified. A 22 gauge $150 \mathrm{~mm}$ Stimuplex needle was inserted in plane through the rectus abdominis muscle $2-3 \mathrm{~cm}$ medial to the probe.

Once the tip was seen between the rectus muscle and transversus abdominis muscle and after negative aspiration the drug was injected and hydrodissection demonstrated. The drug injectant was loaded by another Anaesthetist and handed to the investigator. At the end of procedure, neuromuscular blockade was reversed with inj. Neostigmine $50 \mathrm{mcg} / \mathrm{kg}$ and atropine $0.01 \mathrm{mg} / \mathrm{kg}$. All patients were given inj. Dexamethasone 8mg and Ondansetron 4mg intravenously for anti-emetic prophylaxis. All patients were extubated uneventfully and kept in PACU for 24 hours. Postoperatively all patients were investigated for pain scores for 24 hours and whenever VAS $>=3$, Inj. Morphine $2 \mathrm{mg}$ was administered. Hemodynamic monitoring and any adverse effects were looked for. The time for the first requirement of morphine and the cumulative dose of morphine for 24 hours were noted. Assuming at least a mean difference of 190 minutes. ${ }^{13}$ between group BD and group B in the time of first rescue analgesia requirement, with a power of $80 \%$, an alpha level of $5 \%$, a sample size of 33 in each group has been calculated.

\section{STATISTICAL ANALYSIS}

The statistical analysis has been performed using SPSS version 21. All the demographic variables are represented using percentages, mean \pm SD. normally distributed variables (Time of rescue analgesia, total morphine requirement) between the groups were compared using independent sample student $t$ test. VAS score between the two groups were represented using median and interquartile range and the comparison has been made using Mann Whitney U test.

\section{RESULTS}

One hundred patients took part in this study and were randomly assigned to the two groups. All ultrasound guided oblique subcostal transversus abdominis plane block were performed as described without any complications. Patient characteristics and perioperative data are shown in Table 1. There were no large differences between in the two groups.

\begin{tabular}{|c|c|c|c|}
\hline Variable & Group BD & Group B & $\begin{array}{c}\text { P } \\
\text { value }\end{array}$ \\
\hline AGE & $42.36+/-9.44$ & $42.3+/-8.49$ & 0.083 \\
\hline ASA(1/2) & $32 / 1.8$ & $30 / 20$ & 1.00 \\
\hline Height(cm) & $\begin{array}{c}156.80+/- \\
6.22\end{array}$ & $\begin{array}{c}157.88+/- \\
5.26\end{array}$ & 0.578 \\
\hline Weight(kg) & $58.09+/-4.60$ & $57.09+/-3.92$ & 0.098 \\
\hline $\begin{array}{c}\text { IO Fentanyl } \\
\text { (mcg) }\end{array}$ & $59.8+/-23.1$ & $16.4+/-21.28$ & 0.067 \\
\hline \multicolumn{3}{|c|}{ Table 1 } \\
\hline
\end{tabular}

\begin{tabular}{|c|c|c|c|}
\hline $\begin{array}{c}\text { Time of first } \\
\text { demand } \\
\text { of Morphine (hrs.) }\end{array}$ & $\begin{array}{c}\mathbf{1 0 . 1 8 + / -} \\
\mathbf{2 . 1 2}\end{array}$ & $\begin{array}{c}\mathbf{5 . 9 1 + / -} \\
\mathbf{1 . 2 3}\end{array}$ & $\mathbf{0 . 0 3 9}$ \\
\hline Av VAS Score & $\begin{array}{c}3.20+/- \\
0.579\end{array}$ & $\begin{array}{c}4.91+/- \\
1.63\end{array}$ & 0.041 \\
\hline 24hr Morphine & $5.96+/-$ & $11.18+/-$ & 0.047 \\
Requirement & 1.08 & 2.23 & \\
\hline \multicolumn{4}{|c|}{ Table 2 } \\
\hline
\end{tabular}

As shown in the above table, there is a statistically significant difference in the time for first morphine and pain score for 24 hours between the two methods. (P value $<0.05$ ).

(*Independent sample $t$ test has been used for the comparison.

** $\mathrm{Z}$ test for comparison of two proportions has been used).

The time for the first demand of rescue analgesia, i.e. morphine was earlier in group B, $5.91 \pm 1.28$ hours as compared to group BD, i.e. $10.18 \pm 2.12$ hours. The total morphine consumption in 24 hours ( $p$ value $<0.05$ ). The average VAS score for the 24 hours was lower in group BD $3.20 \pm 0.579$ than in group B, i.e. $4.91 \pm 1.63$. $(\mathrm{p}<0.05)$.

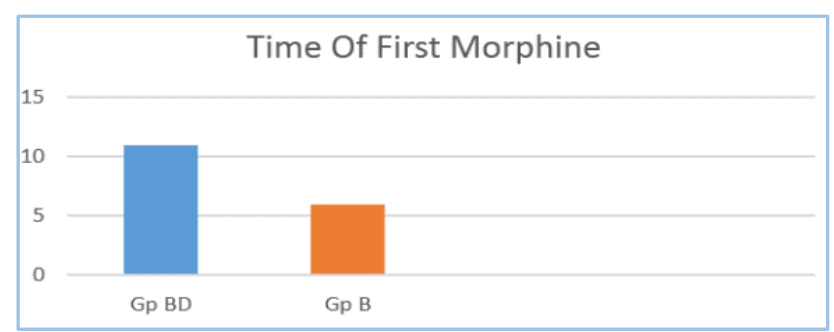

Graph 1: Time of $1^{\text {st }}$ dose of Morphine

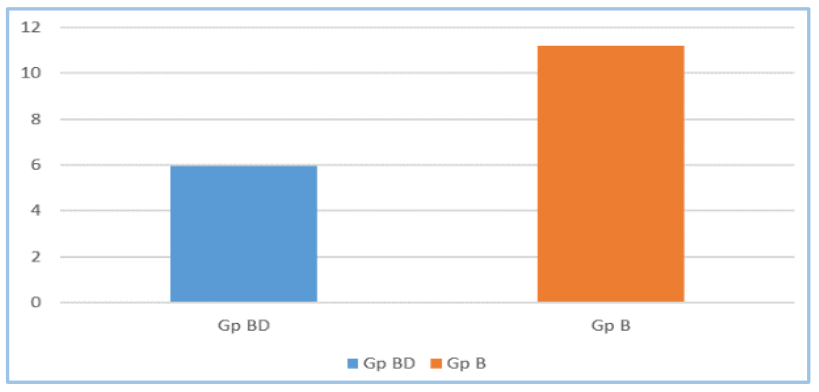

Graph 2: Total 24 hr. Morphine consumption 


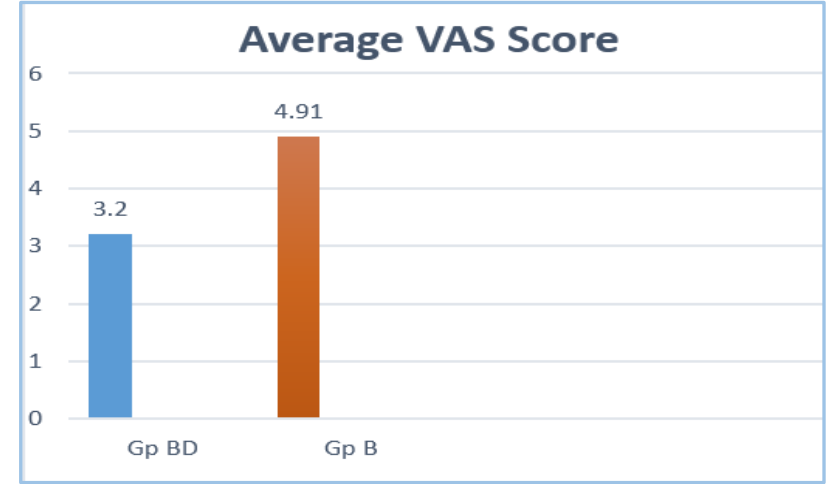

Graph 3: Average VAS Score

\section{DISCUSSION}

This study shows that Dexmedetomidine supplemented in the bilateral oblique subcostal block with $0.25 \%$ bupivacaine in patients undergoing laparoscopic ovarian cystectomy definitely prolonged pain free period postoperatively thus reducing the requirement of morphine. Studies have shown that TAP blocks were associated with early post-operative visual analogue pain score both at rest and during mobilization. ${ }^{13}$ Ultrasound guided oblique subcostal transversus abdominis plane block after laparoscopic sleeve gastrectomy has shown to be a safe and effective method for post-operative analgesia with significant morphine sparing effect. ${ }^{14}$ Brummett et al. ${ }^{11}$ have reported that perineural administration of dexmedetomidine with bupivacaine enhanced local anaesthetic block in rat without inducing neurotoxicity.

There is no study of dexmedetomidine being used in oblique subcostal block for laparoscopic gynaecological studies. Various studies have shown that addition of dexmedetomidine to different local anaesthetic agents in various types of nerve block resulted in prolonged analgesia. ${ }^{15,16}$ Masuki et al. ${ }^{17}$ suggested that dexmedetomidine causes vasoconstriction through alpha 2 adrenergic receptors agonist effect that leads to longer duration of action. Other investigators have suggested a third mechanism of action through alpha 2 adrenergic effect. They attributed it to direct effect on the peripheral nerve activity. ${ }^{18}$

A major disadvantage of oblique subcostal transversus abdominis plane block is the inability to block visceral pain making it suitable for post-operative analgesia in laparoscopic surgeries. In conclusion oblique subcostal transversus plane block is a good alternative for providing analgesia during the post-operative period in laparoscopic ovarian cystectomy surgeries. Ultrasound guided oblique subcostal block using dexmedetomidine with bupivacaine provides longer analgesia with significant morphine sparing effect.

\section{REFERENCES}

1. Rafi AN. Abdominal field block: a new approach via the lumbar triangle. Anaesthesia 2001; 56:1024-6.

2. McDonnell JG, O'Donnell BD, et al. The regional abdominal field infiltration technique computerised tomographic and anatomical identification of a novel approach to the transversus abdominis neurovascular fascial plane. Anaesthesiology 2004; 101:A899.

3. Hebbard P, Fujjiwara Y, Shibata Y, et al. Ultrasound- guided transversus abdominis plane block. Anesth Interns Care 2007; 35(4):616-7.
4. Milan Z, Tabor D, McConnell P, Pickering J, Kocarev M, du Feu F, et al. Three different approaches to transversus abdominis plane block: a cadaveric study. Medicinski Glasnik 2011; 8:181-4.

5. Sivapurapu V, Vasudevan A, Gupta S, et al. Comparison of analgesic efficacy of transversus abdominis plane block with direct infiltration of local anesthetic into surgical incision in lower abdominal gynaecological surgeries. J Anaesthesiol Clin Pharmacol 2013; 29(1):71-5.

6. Coursin DB, Maccioli GA. Dexmedetomidine. Curr Opin Care 2001; 7:221-6.

7. Kanazi GE, Aouad MT, Jabbour-Khory SI, et al. Effect of low dose dexmedetomidine or clonidine on the characteristics of bupivacaine spina; block. Acta Anaesthesiol Scand 2008; 50:222-7.

8. Jain D, Khan RM, Kumar N. Perioperative effect of epidural dexmedetomidine with intrathecal bupivacaine on hemodynamic parameters and quality of analgesia. South Afr J Anaesth Analg 2012; 18:105-9.

9. Gupta R, Verma R, Bogra J, et al. A Comparative study of intrathecal dexmedetomidine and fentanyl as adjuvants to bupivacaine. J Anaesthesiol Clin Pharmacol 2011; 27:33943.

10. El-Hennawy AM, Abd-Elwahab AM, et al. Addition of clonidine or dexmedetomidine to bupivacaine prolongs caudal analgesia in children.

Br J Anaesth 2009; 103:268-74.

11. Brummett CM, Norat MA, Palmisano JM, et al. Perineural administration of dexmedetomidine in combination with bupivacaine enhances sensory and motor blockade in sciatic nerve block without inducing neurotoxicity in rat. Anesthesiology 2008; 109:502-11.

12. Tran TMN, Rozen W, Ashton M, Barrington M, Ivanusic J, Taylor G. Redefining the course of the intercostal nerves: a new understanding of the innervation of the anterior abdominal wall. Clin Anat, 21; 2008; pp. 325-333.

13. Petersen PL, Mathiesen O, Torup H, et al. The transversus abdominis plane block: a valuable option for postoperative analgesia. A topical review. Acta Anaesthesiol Scand, 54 (5) (2010); pp. 529-535.

14. Mohamed Ibrahima, Hossam El Shamaab. Efficacy of ultrasound-guided oblique subcostal transversus abdominis plane block after laparoscopic sleeve gastrectomy: A double blind, randomized, placebo controlled study. Egyptian Journal of Anaesthesia Volume 31; Issue 4: Pages 267-334.

15. Rancourt MP, Albert NT, Côté M, et al. Posterior tibial nerve sensory blockade duration prolonged by adding dexmedetomidine to ropivacaine. Anesth Analg 2012; 115:958-62.

16. Esmaoglu A, Yegenoglu F, Akin A, et al. Dexmedetomidine added to levobupivacaine prolongs axillary brachial plexus block. Anesth Analg 2010; 111:1548-51.

17. Masuki S, Dinenno FA, Joyner MJ, et al. Selective alpha 2adrenergic properties of dexmedetomidine over clonidine in the human forearm. J Appl Physiol 2005; 99:587-92.

18. Eledjam JJ, Deschodt J, Viel EJ, Lubrano JF, Charavel P, d'Athis $\mathrm{F}$, et al. Brachial plexus block with bupivacaine: Effects of added alpha-adrenergic agonists: Comparison between clonidine and epinephrine. Can J Anaesth 1991; 38:870-5. 